\title{
Implementation of Green House Automation using ARM7 Controller
}

\author{
Sushama Arjun Kolhe \\ M.E Student Dept. of Elect \&.Telecomm \\ Engineering J.N.E.C Aurangabad Maharashtra, \\ India
}

\author{
S. A. Annadate \\ Associate Professor. Dept.of. Elect. \&Telecomm \\ Engineering J.N.E.C Aurangabad Maharashtra, \\ India
}

\begin{abstract}
All plants and vegetation require certain conditions for their proper growth. Therefore it is necessary to bring the environmental conditions under control in order to make those conditions as close to the ideal as possible. To create an optimal environment the main climatic and environmental parameters such as temperature, humidity, light intensity, ground water etc need to be controlled to create optimal environment. An automated management of a greenhouse provides the most proper conditions of plant growth. Greenhouse Automation system based on the embedded system is used for the control of the values of temperature, humidity, light intensity and soil moisture that are continuously modified and controlled in order to optimize them to achieve maximum plant growth and yield. A microcontroller receives data on greenhouse environment conditions from a number of sensors and transfers the data to and from a PC via RS 232 port. Accordingly, it changes the state of greenhouse control devices namely, heaters, fans, bulb etc according to the necessary condition of the crops. An integrated Liquid crystal display (LCD) is also used for display of data acquired from the various sensors and the status of the various devices. Keywords: Greenhouse, sensor, Microcontroller, control and Measurement.
\end{abstract}

\section{INTRODUCTION}

The effectiveness in greenhouse crop production depends significantly on the modification of optimal growth conditions to achieve high yield at lower costs, good quality and low environmental load. To achieve these goals several parameters such as ambient temperature and relative humidity must be optimally controlled as per certain criteria through heating, ventilation, etc.[1][2] Environmental control consideration provides an introduction to many options available in greenhouse controls. Over the years the greenhouse systems became more reliable but with increased complexity. Earlier automated control systems consisting independent thermostats and timers provided major advances in efficiency and product quality making growers' lives simpler.

However, many of these control devices and methods cannot deliver the level of automation and efficiency needed in today's dynamic and competitive environment. Several models have been developed to represent greenhouse environments over the years varying in complexity and detail. As operating costs increased and greenhouse systems became increasingly complex, the demand for increased control capability grew. The computer revolution of early 80 s created the opportunity to meet the needs for improved control. In the last decade, there has been tremendous rise in use of computers for green houses. The main improvements in computer based control are found in data logging. [3][5] In order to design successful control system it is important to realize that these parameters are interdependent. This paper presents the system that collects and automatically controls condition of greenhouse environment and crops by using different sensors. The existing control system monitors the temperature and humidity in the green house but other factors like soil moisture, and light intensity are equally important. [4] To make up for this weak point, this paper proposes and collects the information regarding temperature, humidity, soil moisture and light intensity so that the change of condition of crops depending on internal environment factors of greenhouse can be estimated.

\section{SYSTEM DESIGN}

The paper proposed consists of LPC2148 microcontroller, temperature sensor (LM 35), LDR (light dependant resistor) humidity sensor (SY-HS-220) and a soil moisture sensor (simulated using resistor). All these sensors are connected to LPC2148 microcontroller which is main processing unit of the system. The sensors sense different conditions and provide data to microcontroller for processing. From the data obtained from the sensors the program controls the actuator components heater, two cooler fans and pump to achieve the system requirements. It also uses a LCD display to display the data obtained from the sensors.

System architecture is composed of ARM based system board

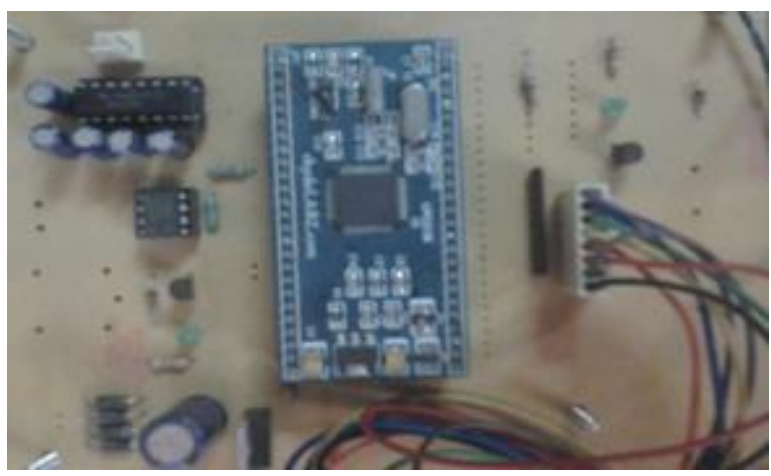

Figure.1: ARM system board 


\subsection{Experimental Setup}

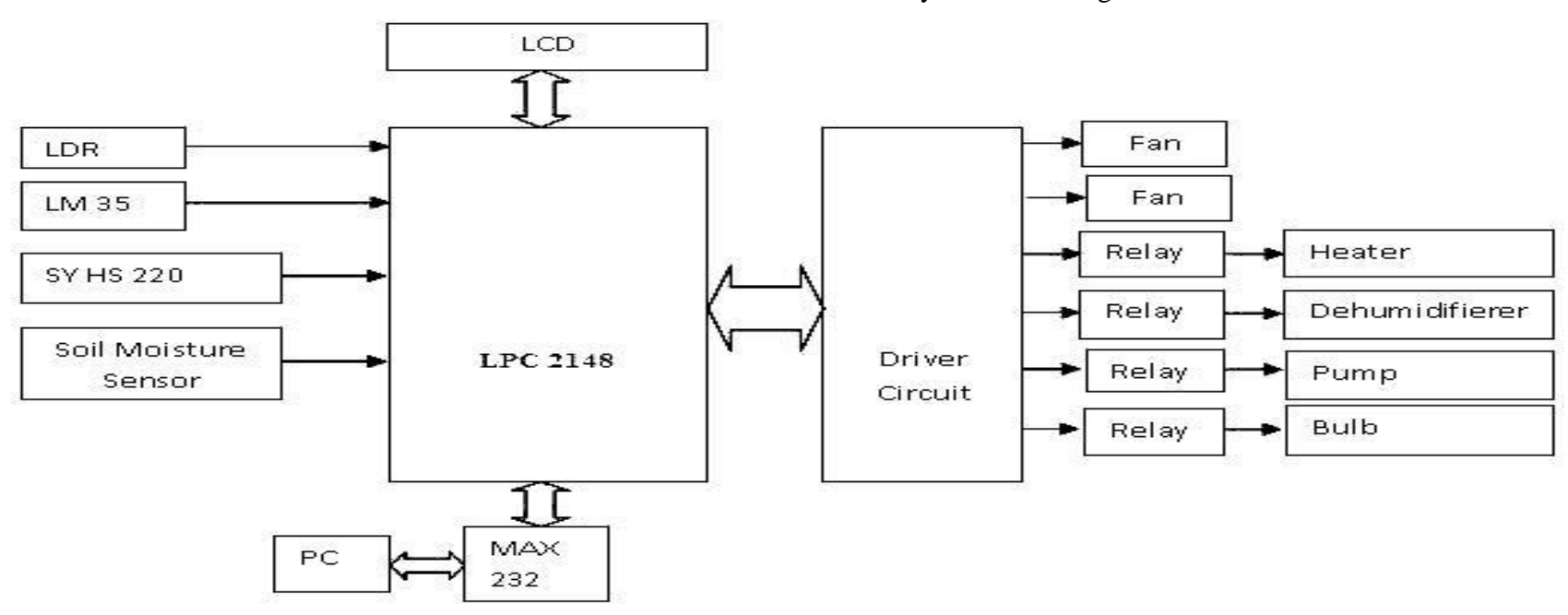

Figure 2: Block diagram of the experimental set up.

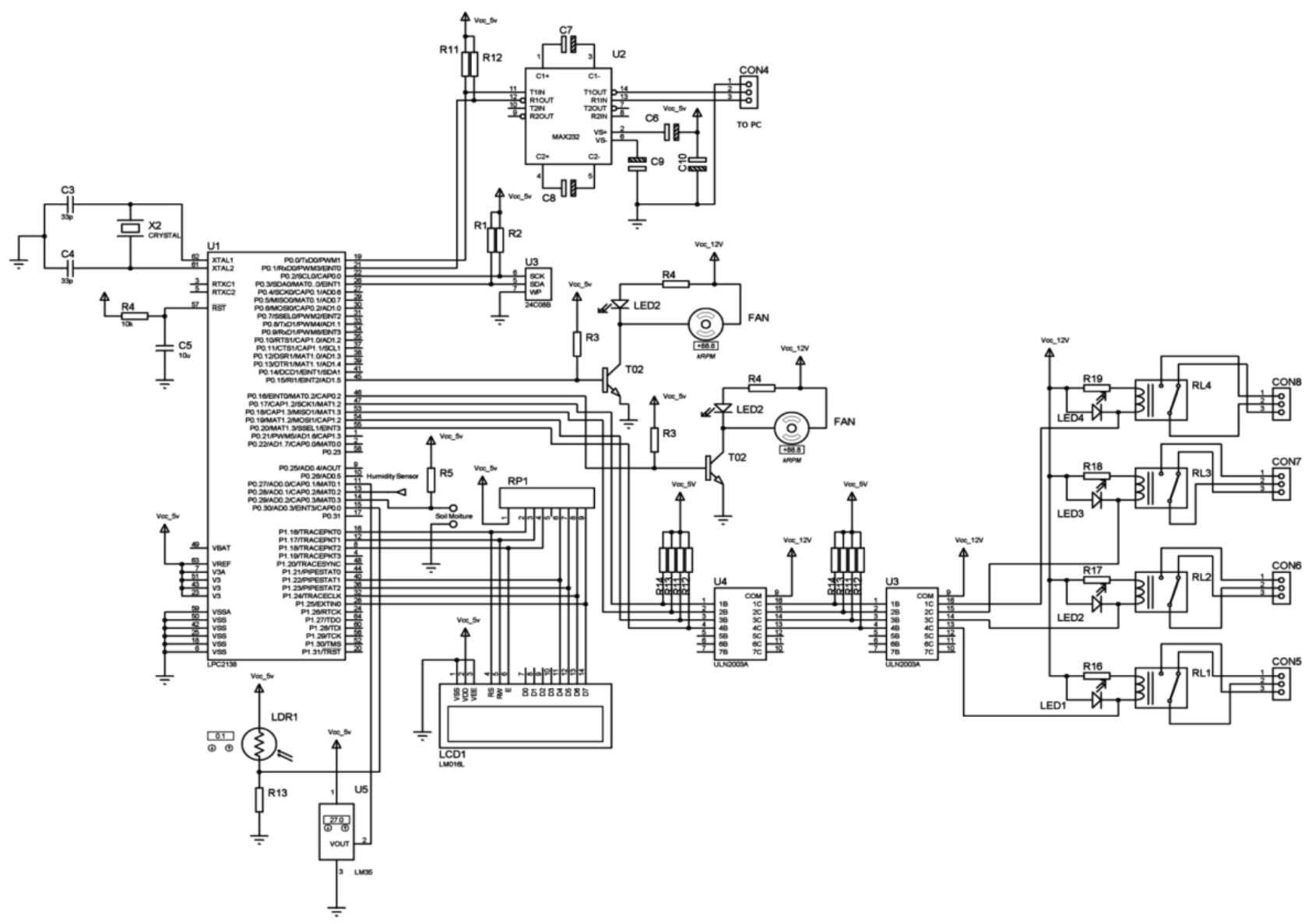

Figure 3 : Schematic diagram of the experimental set up 


\subsubsection{Microcontroller- ARM7 LPC 2148}

This study adopts ARM7 LPC2148, which is a cost effective and high performance and very low power consumption 32-bit microcontroller for the development of system. The ARM architecture is based on Reduced Instruction Set Computer (RISC) principles, the users can take the advantages of the rich and open programming platform resources, to develop different applications. It is based on a 32-bit ARM7TDMI-S CPU with real-time emulation and embedded trace support that combine the microcontroller with $32 \mathrm{kB}$, and $512 \mathrm{kB}$ of embedded high-speed flash memory. A128-bit wide memory interface and unique accelerator architecture enable 32-bit code execution at maximum clock rate. Due to their tiny size and low power consumption, these microcontrollers are ideal for applications. Key features for LPC2148.[6]

1. 32-bit ARM7TDMI-S microcontroller a tiny LQFP64 or HVQFN64 package.

2. $32 \mathrm{kB}$ of on-chip static RAM and $512 \mathrm{kB}$ of on-chip flash program memory.

3. 128-bit wide interface/accelerator enables highspeed $60 \mathrm{MHz}$ operation.

4. In-System Programming/In-Application Programming (ISP/IAP) via on-chip bootloader software. Single flash sector or full chip erase in $400 \mathrm{~ms}$, programming of $256 \mathrm{~B}$ in $1 \mathrm{~ms}$.

5. Two 8-channel 10-bit ADCs provide a total of up to 16 analog inputs, with conversion times as low as $2.44 \mu$ s per channel.

6. Single 10-bit DAC provides variable analog output (LPC2132/34/36/38).

7. Two 32-bit timers/external event counters (with four capture and four compare channels each), PWM unit (six outputs) and watchdog.

8. Low power Real-time clock with independent power and dedicated $32 \mathrm{kHz}$ clock input.

9. Up to forty-seven $5 \mathrm{~V}$ tolerant general purpose $\mathrm{I} / \mathrm{O}$ pins in tiny LQFP64 package.

10. On-chip integrated oscillator operates with external crystal in range of $1 \mathrm{MHz}$ to $30 \mathrm{MHz}$ and with external oscillator up to $50 \mathrm{MHz}$

11. Power saving modes include idle and power-down.

12. CPU operating voltage range of $3.0 \mathrm{~V}$ to $3.6 \mathrm{~V}$ $(3.3 \mathrm{~V} \pm 10 \%)$ with $5 \mathrm{~V}$ tolerant $\mathrm{I} / \mathrm{O}$ pads.

\subsubsection{LM35 Temperature Sensors}

The LM35 series are precision integrated-circuit temperature sensors, whose output voltage is linearly proportional to the Celsius (Centigrade) temperature. The LM35 thus has an advantage over linear temperature sensors calibrated in - Kelvin, as the user is not required to subtract a large constant voltage from its output to obtain convenient centigrade scaling. Features are as follows. [7]

1. Calibrated directly in ${ }^{\circ}$ Celsius (Centigrade)

2. Linear $+10.0 \mathrm{mV} /{ }^{\circ} \mathrm{C}$ scale factor

3. $0.5^{\circ} \mathrm{C}$ accuracy guaranteeable $\left(\right.$ at $\left.+25^{\circ} \mathrm{C}\right)$

4. Rated for full $-55^{\circ}$ to $+150^{\circ} \mathrm{C}$ range

5. Suitable for remote applications

6. Low cost due to wafer-level trimming

7. Operates from 4 to 30 volts
8. Less than $60 \mu \mathrm{A}$ current drain

9.Low self-heating, $0.08^{\circ} \mathrm{C}$ in still air

10 . Nonlinearity only $\pm 1 / 4^{\circ} \mathrm{C}$ typical

11. Low impedance output, $0.1 \mathrm{~W}$ for $1 \mathrm{~mA}$ load.

LM 35 is calibrated in ${ }^{\circ} \mathrm{C}$ and is linear in $+10 \mathrm{mV} /{ }^{\circ} \mathrm{C}$ scale factor with $0.5^{\circ} \mathrm{C}$ accuracy .The calibration curve given here will make the scenario clear

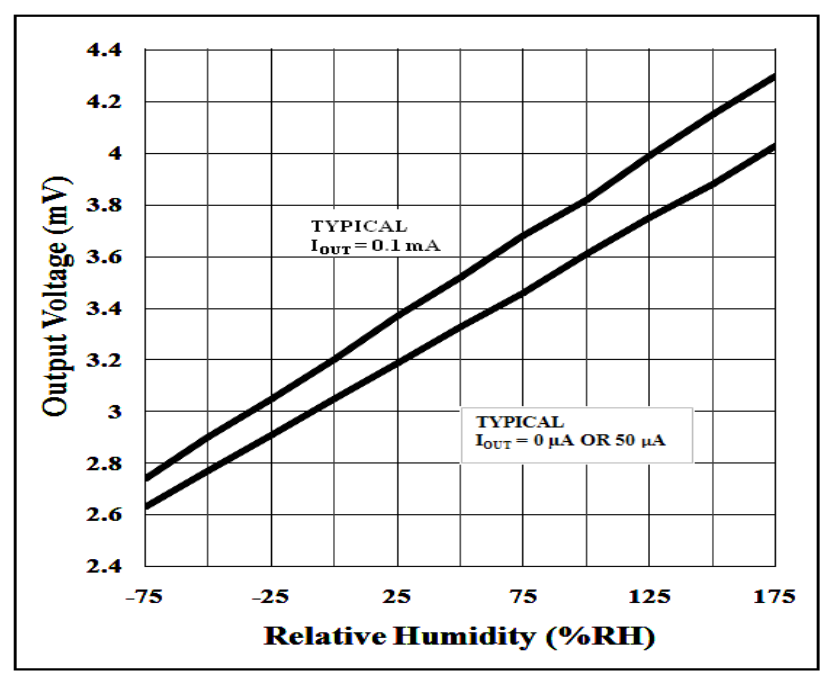

Figure 4: Voltage VS Temperature Calibration Curve

\subsubsection{Humidity Sensor (SY-HS-220) [8]}

These modules convert relative humidity to the output voltage. Humidity Sensor is designed to operate on DC $5 \mathrm{~V}$, $0-60^{\circ} \mathrm{c}, 30-90^{\circ} \mathrm{c} \mathrm{RH}$, output voltage is DC $1.980 \mathrm{mv} \pm$ at 25 ${ }^{\circ} \mathrm{c} 60 \%$ RH.

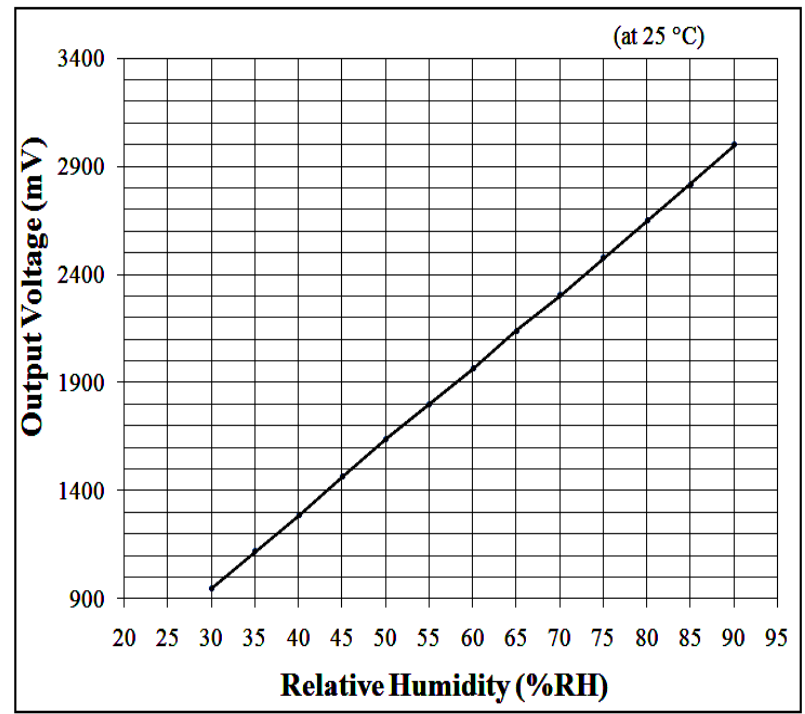

Figure 5 : Standard Characteristics of Humidity sensor 


\subsubsection{LDR- Light Dependent Resistor [9]}

Two cadmium sulphide (cds) photoconductive cells with spectral responses similar to that of the human eye. The cell resistance falls with increasing light intensity. Applications include smoke detection, automatic lighting control, and batch counting and burglar alarm systems.

\subsubsection{Soil Moisture Sensor:}

This basic cheap soil moisture sensor consists of two probes (the metal rods or Ordinary galvanized nails) held apart at a fixed distance by some insulating material. They are used to sense soil moisture. Two pieces of wire, each 2' long, and strip $1 / 2$ " off the ends. One end of each wire is wrapped around the head of each nail. Cover the wire-nail connection with a generous amount of solder. By measuring the resistance between the two nails stuck in the soil, water requirement of soil can be determined. More the water in the soil more is the conductivity .It uses the two probes to pass current through the soil and to measure the resistance to get the moisture level. More water makes the soil more conductive (less resistance), while for dry soil conductivity is poor (more resistance),

\section{SYSTEM OPERATION}

Initially a temperature point is set. The temperature sensor senses the change in input temperature .This analog signal is after signal conditioning, is given to the analog input pin of the micro-controller. This micro-controller converts it to digital format using on chip ADC .If the temperature sensed is below the low limit set, the controller unit will start the heater. Once it reaches the set limit it will switch off the heater. If the temperature sensed is above the set limit, it will start the blower to bring the temperature down. Once it reaches below a set point, it will switch off the blower. In this way, temperature is controlled.

Similarly, an intensity of light can be controlled. Initially a intensity point is set. Light dependent resistor senses the change in input intensity of light. If the intensity of light sensed is below the low limit set, the controller unit will switch on bulb. Once it reaches the set limit it will switch off the bulb. In this way, intensity of light is controlled.

Humidity can be control by using a humidity sensor. Initially Humidity is set. Humidity Sensor senses the change in humidity. If the humidity sensed is below the low limit set, the controller unit will turn on the dehumidifier. Once it reaches the set limit it will switch on the humidifier. In this way, humidity is controlled

If the soil moisture is less than the low limit pump will turn on. If the soil moisture is greater than the high limit then pump will turn off.

After it senses intensity of temperature, light and humidity, soil moisture it gives digital display at the output on LCD.

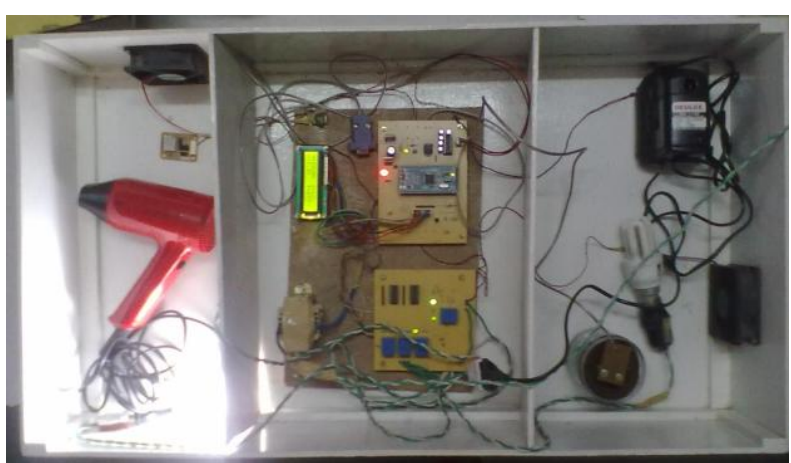

Figure 6 Picture of implemented Green house system.

\section{SOFTWARE DESCRIPTION:}

Software is developed in embedded C language. VB6 software is used for PC Side Algorithm for online monitoring and controlling of light Intensity, temperature, humidity, and soil moisture.

Algorithm for Greenhouse automation is as follows.

1. Start

2. Initialize ADC.

3. Initialize LCD.

4. Initialize UART

5. Get all set points from EEPROM

6. Get feedback from Temperature sensor

7. If temperature $>$ Set temperature then turn $\mathrm{ON}$ the Cooler(FAN)

8. If temperature $<$ Set temperature then turn $\mathrm{ON}$ the Heater

9. Get feedback from Humidity sensor

10. If humidity $>$ Set humidity then turn $\mathrm{ON}$ the Humidifier

11. If humidity $<$ Set humidity then turn $\mathrm{ON}$ the Dehumidifier

12. Get feedback from LDR

13. If light intensity $<$ Set light intensity then turn ON the Bulb

14. If light intensity > Set light intensity then turn OFF the Bulb

15. Get feedback from Soil moisture sensor

16. If soil moisture $<$ Set soil moisture then turn $\mathrm{ON}$ the Pump

17. If soil moisture $>$ Set soil moisture then turn OFF the Pump

18. If data received from $\mathrm{PC}$, if $\mathrm{NO}$ go to ' 6 '

19. If data received $=$ ' $\mathrm{I}$ ' then send all info to $\mathrm{PC}$ and go to ' 6 '

20. If data received $=$ ' $T$ ' then update set temperature and and go to ' 6 '

21. If data received $=$ ' $H$ ' then update set humidity and go to ' 6 '

22. If data received $=$ ' $L$ ' then update set light intensity and go to ' 6 '

23. Go to ' 6 '

24. Stop. 


\section{RESULT AND CONCLUSIONS}

In this project we allow the users to set the conditions appropriate to the crop is growing. This will be done via PC interface. The more accurate a sensor is, better it will perform.

The unit will monitor the conditions of various parameter considerations and take appropriate action. Action taken is as follows:

- If temperature is lower than the set point: Heater relay will Turn ON and fan will turn OFF.

- If temperature is higher than the set point: then Fan will be Turned ON and heater will turn OFF.

- If Humidity is higher than the set point: then Fan / Humidifier will be Turned ON and heater / Dehumidifier will turn OFF.

- If Humidity is lower than the set point: then Fan / Humidifier will be Turned OFF and heater / Dehumidifier will turn ON.

- IIf temperature is higher than the set point: then Fan will be Turned ON and heater will turn OFF.

- If Light Intensity is higher than the set point: turn OFF the bulb.

- If Light Intensity is lower than the set point: turn ON the bulb.

- If soil moisture is higher than 70\%: Pump will be turned OFF

- If soil moisture is lower than 30\%: Pump will be turned ON.

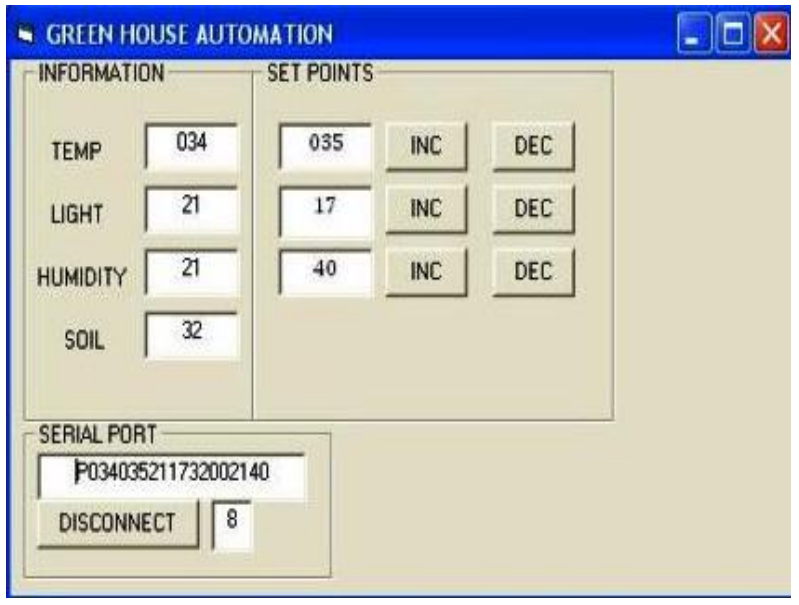

Figure 7: Main graphical user interface of the Greenhouse Automation Software.
The relays work properly at any set temperature. humidity light intensity and soil moisture value. The on/off condition of the relay is set by making loop of two values to avoid continuous switching on/off of relays. We measure light intensity in volts so the system can be enhanced by using a LUX meter to calibrate the unit.

\section{ACKNOWLEDGEMENT}

Our thanks to the SPJ Embedded System, Pune and DNA technology Nasik and for their support.I

\section{REFERENCES}

[1] Hartmut Pohlheim, Adolf Heißner" Optimal Control of

Greenhouse Climate using Real-World Weather Data and Evolutionary Algorithms"

[2] Mahmou Omid. " A Computer-Based Monitoring system to Maintain Optimum Air Temperature and Relative Humidity in Greenhouses" international journal of agriculture \& biology.1560-8530/2004/06-5-869-873.

[3]A.Goswami, T. Bezboruah and K.C.Sarma "Design of an embedded system for monitoring and controlling temperature and light. ", International Journal of Electronic Engineering Research/ volume 1 Number 1 (2009) pp 27-36

[4]Beomjin Kang, D.Park "Study on the greenhouse auto control system based on wireless sensor network", IEEE, 2008

[5]S.H. Sadati , A.M.Sahari, "Design and Simulation of an automated system for greenhouse using LabVIEW" American-Eurasian J.Agric and Environ Sci, 3(2):279284,2008 ISSN 1818-6769.

[6]http://www.nxp.com/documentts/data_sheet/LPC2131_32_ 34_36_38.pdf

[7]National Semiconductor Corporation, LM35 datasheet, precision centigrade Temperature sensors, Atmel data book,

[8] SY-SH-220 datasheet precision humidity sensor.

[9]http://www.biltek.tubitak.gov.tr/gelisim/elektronik/dosyala r/40/LDR_NSL19_M51.pdf

[10]Muhammad Ali Mazidi and Janice Gillispe Mazidi, "The 8051 Microcontroller and EmbeddedSystems," Pearson Education Ltd., India, 2007.10 